Contato para correspondência: Liana Kalczuk

E-mail:

lianakalczuk@gmail.com

Conflito de interesse: Não

Financiamento: Recursos próprios

Recebido: 12/08/2021

Aprovado: 23/08/2021

\title{
AFECÇÕES DERMATOLÓGICAS EM PÉS DE MILITARES: REVISÃO NARRATIVA DA LITERATURA
}

\section{Dermatological conditions on military feet: narrative litera- ture review}

Liana Kalczuk', Priscila Correia Fernandes', José Elias Matieli

${ }^{1}$ Instituto Tecnológico de Aeronáutica - ITA

\section{Resumo}

Este estudo teve como objetivo construir uma revisão bibliográfica Narrativa, versando sobre histórico, etiologia, diagnóstico, prevenção e tratamento das afecções dermatológicas mais comuns em pés de militares a partir da análise de artigos científicos sobre o tema. Foi realizada uma pesquisa nos bancos de dados PubMed, Lilacs e SciELO, em língua inglesa e portuguesa, com os descritores "trench foot", "military", "dermatophytosis" e "Tinea pedis", publicados no período entre 2002 e 2021. O pé de trincheira e as infecções fúngicas e bacterianas são as principais afecções que acometem os pés de militares. O uso constante de botas, a facilidade de contágio no ambiente militar e principalmente o ambiente interno do calçado são considerados fatores de risco. A prevenção e o tratamento destas afecções são ainda desafiadores. A desinfecção do calçado por gás ozônio mostra-se como estratégia preventiva destas condições. Enfatizase a complementação do tratamento preventivo com a desinfecção das botas militares como formas de se evitar baixas em missões por estas afecções podais, especialmente as infecciosas. Apesar de responder por expressivas baixas em cenários militares, as afecções nos pés continuam prevalentes neste segmento social. Estratégias preventivas devem ser mais sedimentadas nesta população. A introdução de tecnologias de desinfecção de botas parece ser promissora na redução da incidência das infecções podais.

Palavras-chave: pé de trincheira; militar; dermatofitoses; Tinea pedis.

\begin{abstract}
The aim of this study is to present an narrative literature review about the historical, etiological, diagnoses, prevention and treatment of the most prevalent foot dermatological conditions in the military. A research in PubMed, Lilacs and Scielo digital libraries was performed, in English and Portuguese, using the key words: "trench foot", "military", "dermatophytosis" and "Tinea pedis" between 2002 and 2021. Trench foot, dermatophytosis and bacterial infections are the principal pathological foot conditions among the military. Regular use of military boots, contagiousness and especially the internal shoe environment are risk factors. Prevention and treatment of these conditions are still challenging. Ozone gas shoes disinfection can be a useful strategy for their prevention. Preventive strategies together with boots disinfection can avoid casualties during deployment.

Keywords: "trench foot",'military", "dermatophytosis"','Tinea pedis".
\end{abstract}




\section{Introdução}

As doenças dermatológicas dos pés de militares foram e ainda são responsáveis por incontáveis baixas nos teatros de operações da atualidade, em todos os ambientes do planeta'. Desde as comuns dermatofitoses dos pés (Tinea pedis), passando pelas infecções bacterianas até o famoso "pé de trincheira" das duas grandes guerras mundiais, as afecções podais respondem por significativo número de baixas de combatentes em diversos tipos de missões. ${ }^{2}$

Nos cenários atuais, onde os militares são deslocados para locais de combate, treinamento ou assistência em catástrofes, o cuidado com os pés ocupa lugar central na prevenção de baixas. Vários estudos apontam que os militares são população de risco para afecções nos pés. . $^{3,45,6,7,8}$

Sabe-se que botas e meias encharcadas ou úmidas por água ou suor são um ambiente propício para a maceração da pele dos pés e a proliferação de fungos e bactérias capazes de danificar os tecidos. ${ }^{3,4,5,6}$ As dermatofitoses dos pés acometem até $70 \%$ do efetivo militar em vários países ${ }^{4}$ e a colonização das lesões fúngicas em membros inferiores por bactérias resistentes à meticilina (MRSA) responde atualmente por $4 \%$ das internações e óbitos nas Forças Armadas dos EUA. ${ }^{9}$

Dada à importância do tema para os militares, a literatura cita várias estratégias para a prevenção destes problemas, como medidas de higiene podal, arejamento ${ }^{10}$ e uso preventivo de antifúngicos tópicos ${ }^{11,12,13}$ e o que pode contribuir para a resistência fúngica a agentes antifúngicos. ${ }^{14} \mathrm{~A}$ desinfecção dos calçados tem sido foco de estudos nos últimos anos, uma vez que os calçados foram identificados como um grande reservatório de microrganismos responsáveis por infecções podais. ${ }^{15,16}$ Luz ultravioleta e gás ozônio têm sido preconizados para esta desinfecção. 17,18,19,20,21,22 Técnicas de biologia molecular têm sido usadas para identificar diferentes cepas de microrganismos patogênicos em dermatofitoses nos pés, clarificando a resistência fúngica por meio do DNA.23,24 Este artigo faz uma revisão narrativa da literatura abordando a história das afecções nos pés de militares, etiologia, incidência destas lesões entre militares na atualidade e estratégias de enfrentamento, tendo sido consultadas as bibliotecas eletrônicas do PuBMed, LILACS, BIREME.

\section{Métodos}

Foi realizada uma busca bibliográfica por artigos nas bases eletrônicas de dados do National Center of Biotechnology Information US (PubMed), da Literatura Latino-americana e do Caribe em Ciências da Saúde ou Biblioteca Regional de Medicina (LILACS/BIREME), e no Google Scholar, nas línguas inglesa e portuguesa. Foram elencados os artigos publicados entre os anos de 2002 e 2021, usando-se os seguintes Descritores em Ciências da Saúde (DeCS) ou palavras-chave: "trench foot", "dermatophytosis", "military" e "Tinea pedis" e seus equivalentes em português. Cada DeCS foi utilizado de modo isolado ou combinado.

O uso destas palavras-chave resultou em 589 artigos nas bases de dados utilizadas. Neste conjunto de artigos, foram utilizadas as seguintes ferramentas automáticas de busca: a. artigos com texto integral disponível, b. em idiomas português e inglês e 3. publicados entre 2002 e 2021, resultando em 218 artigos (198 no PubMed, 11 no LILACS/BIREME e 9 no Google Scholar). A partir da leitura de seus resumos, foram selecionados 38 artigos que estavam dentro do escopo do trabalho. A exclusão foi feita de forma manual e o critério de exclusão principal foi dos artigos que não tratavam do ambiente militar. Como critérios de exclusão secundários, utilizamos: artigos duplicados, artigos que não tivessem como foco aspectos médicos (artigos de história geral que apenas mencionavam os pés-de-trincheira), artigos que tratavam de outras afecções e aqueles que apenas citavam as dermatofitoses podais.

Durante a leitura dos textos completos, foram ainda incluídos nas análises três dos artigos por meio da técnica de Snowballing a partir da bibliografia citada (backward snowballing) de artigos selecionados pelo método anterior (string). ${ }^{1}$

O elenco dos 38 artigos selecionados foi lido em sua versão completa, de modo a fornecer subsídios para a montagem deste artigo nos subtítulos Epidemiologia; Pé de trincheira, Diagnóstico e Prevenção e Tratamento. Sites comerciais também foram visitados para compor o subtítulo Prevenção e Tratamento.

\section{Resultados}

Foram selecionados para compor este trabalho 38 artigos, teses ou monografias, Estes 38 trabalhos foram divididos de acordo com as seções "Epidemiologia", "Pé de trincheira", "Diagnóstico" e "Prevenção e tratamento". O fluxograma (Fig. 1) a seguir mostra o método usado nesta revisão bibliográfica e os resultados obtidos:

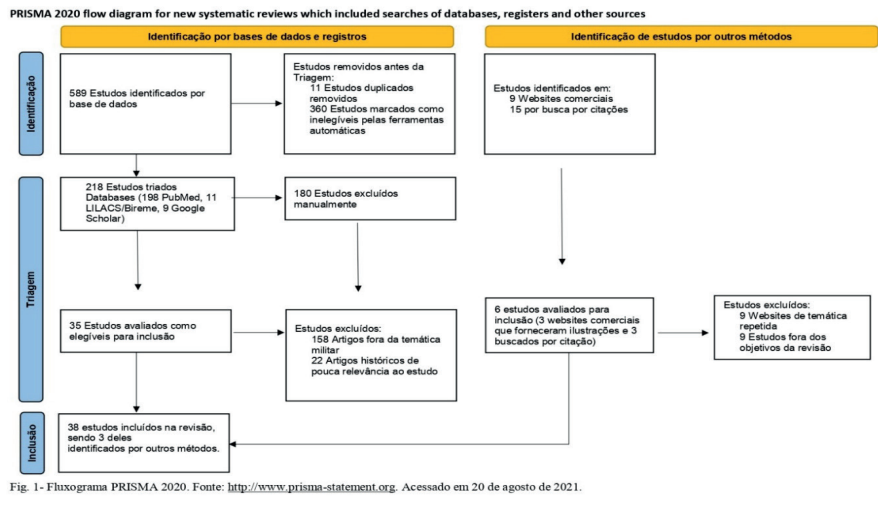




\section{Epidemiologia}

Os militares são bastante afetados pelas condições infecciosas dermatológicas nos pés, sendo grupo de risco para estas condições. ${ }^{3,6}$ As condições de trabalho dos militares facilitam o aparecimento de feridas resultantes de contusões, arranhões, cortes e maceração dos tecidos, especialmente de membros inferiores. Todas as feridas militares apresentam algum grau de colonização bacteriana ou fúngica e estão sujeitas à infecção. Feridas infectadas em militares são dolorosas, de difícil cicatrização, frequentemente levam à hospitalização e podem levar à morte. ${ }^{3}$

Sabe-se que as dermatofitoses nos pés (infecções fúngicas na pele e unhas causadas por dermatófitos, grupo de fungos queratolíticos capazes de infectar as camadas superficiais da pele, unhas e pêlos de animais e humanos) comprometem até $70 \%$ do efetivo militar, dependendo das condições ambientais do calçado, como umidade e frequência de higienização. ${ }^{4}$

As cinco condições dermatológicas mais prevalentes em militares são as infecções fúngicas (dermatofitoses), as dermatites alérgicas, as mordidas de inseto, infecções bacterianas e a acne. Já nos civis, prevalecem as dermatites alérgicas, a acne, os tumores benignos da pele, as infecções virais e as desordens pigmentares, nesta ordem. ${ }^{5}$

Cerca de 1300 soldados coreanos foram avaliados dermatologicamente e constatou-se que a Tinea pedis foi a segunda enfermidade mais prevalente, precedida pela acne. Os militares são grupo de risco para infecções fúngicas podais devido ao uso de botas de couro oclusivas, ao trauma podal ocasionado por exercícios físicos e à higiene deficiente ${ }^{8}$.

Segundo metanálise publicada em 2018, ${ }^{1}$ a incidência de infecções fúngicas como a Tinea pedis é significativamente maior em militares do que em civis, atingindo mais homens do que mulheres e é altamente prevalente em militares em missões de combate e de paz, representado um problema médico e social neste grupo em particular, sendo que militares da Infantaria de patentes mais baixas são ainda mais atingidos. Segundo este estudo, as dermatofitoses de pés atingem cerca de $60 \%$ dos militares israelenses, $90 \%$ nas forças de defesa do Japão, $60 \%$ dos militares coreanos, $49 \%$ dos militares envolvidos na Guerra da Croácia e 32\% dos militares na Dinamarca. Entre policiais sul-africanos, o índice é de 76,9\%. Em países onde predominam climas desérticos, como a Líbia, o índice é menor, de $25 \%$, chegando a somente $2,8 \%$ no Paquistão. No Brasil, estima-se que $45 \%$ dos soldados tenham frieiras ou pé de atleta, causados principalmente por T. rubrum, $T$. mentagrophytes, T. tonsurans, $T$. verrucosum e T. interdigitale. As roupas fechadas, o uso constante de botas, o estresse físico e emocional, o suor e o compartilhamento de estruturas como banheiros, chuveiros e piscinas facilitam o desenvolvimento das dermatofitoses.

Em outro estudo, ${ }^{7}$ soldados israelenses tiveram seus pés analisados pelo Athlete's Foot Severity Index, onde se verificou que $60 \%$ dos soldados analisados eram acometidos pela Tinea pedis, sendo esta condição positivamente associada ao sexo masculino e à Infantaria. $\mathrm{O}$ uso de banheiros compartilhados e de botas militares por longos períodos são as explicações dos autores para esta associação positiva.

Nos Estados Unidos, sabe-se que as infecções de pele e tecidos moles por MRSA (methicillin-resistant Staphylococcus aureus) tornaram-se endêmicas em algumas populações, como entre recrutas de infantaria. ${ }^{32,33} \mathrm{As}$ infecções por MRSA são bastante prevalentes entre militares ao redor do globo há décadas e a literatura mostra a preocupação constante com o monitoramento desta infecção dentro e fora dos Estados Unidos. ${ }^{34}$ Nos dois primeiros anos de serviço militar, as internações por MRSA só perdem para as de influenza e pneumonia. ${ }^{9}$

\section{Pé de trincheira}

As condições patológicas dos pés de combatentes são descritas na literatura há mais de dois séculos. A mais famosa delas, o pé de trincheira, foi primeiramente descrita pelo médico Dr. Dominique Jean Larrey, cirurgião do exército de Napoleão Bonaparte, em 1812, como sendo decorrente da imersão dos pés em um meio ambiente úmido, frio e sem condições sanitárias adequadas. ${ }^{2}$ Na Primeira Guerra Mundial, milhares de soldados britânicos pereceram por causa desta condição. Embora muito já tenha sido publicado a respeito da prevenção do pé de trincheira, os britânicos tiveram que novamente lidar com a afecção na Guerra das Malvinas, em $1982 .{ }^{25} \mathrm{~A}$ figura abaixo é uma fotografia dos pés de um soldado acometido pelo "pé de trincheira" e que os teve amputados:

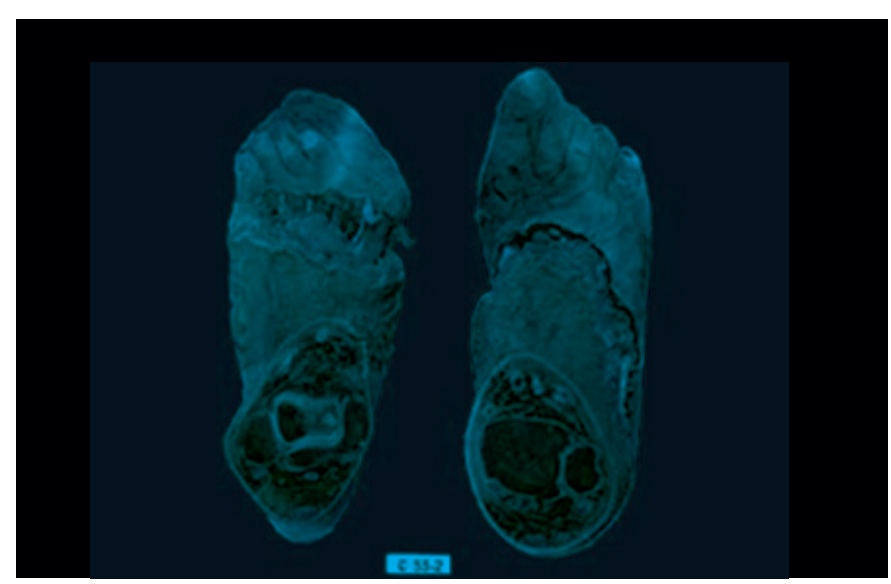

Figura 2. Robin A. Cooke, Arquivos. Pés de trincheira amputados. I World War. Fonte: https://www.tropmed.org/wp-content/uploads/2018/05/Prof-Cooke. pdf. Acessado em 22 de abril de 2021. 
O pé de trincheira ou pé de vala é uma entidade patológica ainda não totalmente compreendida. ${ }^{26}$ É considerado uma lesão não congelante frequentemente complicada por infecção, na qual a exposição a temperaturas frias ou quentes, combinada com a umidade, resulta em uma vasoneuropatia periférica. A presença de traumas físicos, infecções bacterianas ou fúngicas, desnutrição, hipertensão venosa e linfedema significam que alguns indivíduos apresentam maior risco de pé de trincheira. $O$ pé de trincheira pode ser evitado aquecendo os pés, trocando-se as meias, mantendo-se ativo, esfregando-se a pele com óleo e inspecionando regularmente os pés. ${ }^{27}$

Contudo, o pé de trincheira pode ocorrer em temperaturas bem superiores aos $16^{\circ} \mathrm{C}$ (a hiperhidrose, condição de suor excessivo, pode ocorrer nos pés dentro de botas em locais quentes), podendo se desenvolver num prazo de pouco mais de $10 \mathrm{~h}$, ou seja, é uma condição de instalação muito rápida. ${ }^{27}$

Devido às condições ambientais crônicas de umidade, frio ou calor excessivo dentro dos calçados, ocorre vasoconstrição dos capilares, levando à isquemia dos tecidos, maceração da pele e por seguinte necrose tecidual. Nas primeiras 24 a 48h, há alternância entre vasoconstrição e vasodilatação, com dor em queimação, edema, equimose e ulceração. Após 2 a 6 semanas, sobrevêm cianose e sensibilidade aumentada ao frio. $O$ tratamento preferencial deve ser feito na fase de 24 a $48 \mathrm{~h}$ após exposição ao frio, com arejamento do membro ao ar quente e seco. ${ }^{28}$

Os sinais e sintomas clínicos do pé de trincheira incluem a sensação de dor e formigamento nos pés, seguido por dormência e edema (os pés podem ficar com o dobro do tamanho normal) e alterações na coloração da pele (vermelhidão ou arroxeamento). Conforme a doença progride, há piora da dor e podem ser visualizadas áreas de necrose com odor fétido característico e abrem-se fissuras na pele por onde penetram microrganismos oportunistas. ${ }^{29} \mathrm{~A}$ pele, de tão macerada e necrosada, costuma se soltar dos pés. Se a condição não receber tratamento, a gangrena se instalará e o único tratamento disponível para se evitar a sepse e a morte do doente é a amputação do pé afetado. ${ }^{28}$

Atualmente, a condição é vista em triatletas, militares em missões de combate ou paz ao redor do mundo, moradores de rua, pescadores..$^{30}$ Por meio de biópsias e avaliações sensoriais de soldados que tinham sofrido danos por frio nos pés há mais de 4 meses, o pé de trincheira foi classificado como uma neurovasopatia dolorosa, na qual a isquemia causada pelo frio produz um aumento da vascularização do pé, em conjunto com a presença de fibras nervosas anormais e desproporcionais.

As figuras abaixo ilustram a prevenção dos pés de trincheira (esquerda) e o pé de trincheira em atletas (direita):

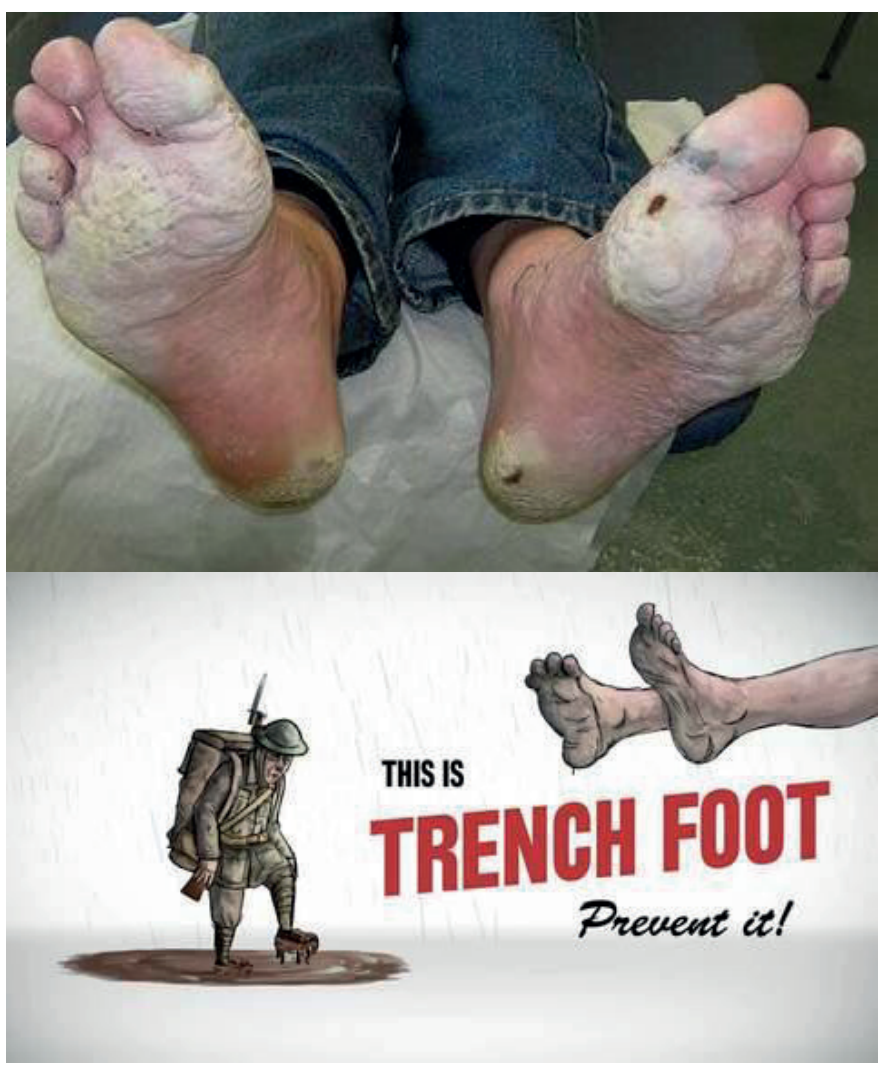

Figura 3. À esquerda, cartaz da I Guerra Mundial alertando para a prevenção do pé de trincheira. À direita, pé de triatleta após competição. Fonte: https:// www.hobyanddistricthistory.co.uk/trench-foot/ e https://www.foot-painexplored.com/trench-foot.html. Acessado em 22 de abril de 2021.

A literatura descreve algumas lesões nos pés observadas nos corredores e caminhantes da região do Grand Canyon, nos Estados Unidos, onde as temperaturas atingem facilmente os $40^{\circ} \mathrm{C}$, podendo chegar a $50^{\circ} \mathrm{C}$ em alguns locais. Localmente, estas lesões são chamadas "Tolio", em alusão à poliomielite, já que são altamente incapacitantes. Consistem basicamente na queratólise dos pés por bactérias do calçado do caminhante, especialmente em calçados fechados e apertados, com grande condição de umidade e calor. ${ }^{31}$

\section{Diagnóstico}

Em um estudo envolvendo militares na região Centro-Oeste do Brasil, ${ }^{35}$ verificou-se que o gênero Trichophyton foi o mais prevalente entre os dermatófitos encontrados nas lesões fúngicas entre militares, infectando preferencialmente a pele (83\%) e as unhas (17\%). O alto risco de infecções fúngicas no grupo militares deve-se ao clima da região, à necessidade do uso da bota diariamente, ao compartilhamento de vestiários e à higienização insuficiente de meias, pés e calçados.

Em revisão sistemática da literatura sobre dermatofitoses no Brasil, ${ }^{36}$ verificou-se que a exata prevalência destas é desconhecida, acometendo cerca de $25 \%$ das populações estudadas 
por cultura de fungos e biologia molecular. T. rubrum, T. interdigitale e T. mentagrophytes foram os microrganismos encontrados mais comumente nas lesões.

Por meio de biologia molecular de alto desempenho, sorologia e ensaios microbiológicos padronizados, foram analisados abscessos cutâneos e celulites em soldados americanos em período de treinamento, verificando-se que a celulite foi associada aos membros inferiores e o abscesso ao $S$. aureus. O Rhodanobacter terrae foi o microrganismo mais prevalente nos microbiomas estudados. Embora as bactérias encontradas nos sítios investigados sejam comuns às infecções de pele e tecidos moles, a tecnologia molecular de alto desempenho mostrou a presença de bactérias atípicas, o que pode indicar um novo papel destas na patogênese da celulite. ${ }^{6}$

Também por meio de técnicas de biologia molecular (PCR), T. mentagrophytes e T. interdigitale foram identificados como os fungos mais prevalentes em amostras de pele, cabelo e unhas na região subtropical do nordeste do Irã. O T. benhamia aparece como novo agente etiológico de dermatofitoses naquela região. ${ }^{37}$

Foi realizado um re sequenciamento do genoma de 48 amostras de T. rubrum, agente etiológico de dermatofitoses ao redor do mundo, para uma melhor percepção da resistência deste a drogas antifúngicas. Sua estrutura populacional pode ser subdividida em apenas dois grupos, com baixa diversidade genética. O gene TERG_08771 está associado à resistência dele ao voriconazol. Outros estudos moleculares são necessários para uma melhor compreensão deste fungo. ${ }^{23}$

Usando-se a técnica de NGS (non-transcribed spacer region) como marcador molecular, treze diferentes subespécies foram caracterizadas a partir de 64 amostras de T.mentagrophytes, obtidas clinicamente e isoladas por características fenotípicas. A caracterização de cepas por técnicas de biologia molecular permite a compreensão de mecanismos de resistência fúngica a antimicrobianos. ${ }^{24}$

Em um estudo observacional inédito envolvendo 420 pacientes, ${ }^{15}$ verificou-se que quanto maior a temperatura, a umidade e o ponto de orvalho dentro do calçado maior era a incidência de T.pedis. Esta incidência era maior em homens do que em mulheres e tinha relação com a estação do ano e o tipo de sapato usado: sapatos fechados, como botas, e de material sintético, ofereceram as melhores condições de temperatura e umidade para o aparecimento da dermatofitose nos pés. Desta forma, foi demonstrado que a incidência de T. pedis está relacionada ao meio ambiente interno do calçado.

Em um estudo de 2019, ${ }^{16}$ investigou-se a presença de fungos nos sapatos de segurança de trabalhadores de uma fábrica no Japão. Os autores acreditam que a razão pela qual as dermatofitoses continuam presentes na população japonesa, apesar da disponibilidade de agentes antifúngicos, seja principalmente a reinfecção por dermatófitos remanescentes no ambiente, neste caso, no interior dos calçados dos trabaIhadores. Os autores coletaram a poeira de dentro do calçado sobre uma lâmina de vidro, pingaram hidróxido de potássio em solução a $20 \%$ sobre a coleta e aqueceram em bico de Bunsen por um minuto. As amostras foram observadas em microscopia óptica para visualização de hifas e leveduras. Cerca de $40 \%$ dos calçados de trabalhadores com T. pedis estavam contaminados com Trichophyton spp.

\section{Prevenção e tratamento}

A prevenção das afecções nos pés de militares passa sempre pela retirada rotineira das botas, arejamento, higienização, secagem dos pés e trocas de meias. ${ }^{26}$ Com o objetivo de divulgar estratégias e técnicas de prevenção de afecções nos pés entre militares, foi publicado o "Manual educativo de prevenção do pé de trincheira: validação de um manual educativo para militares do Exército Brasileiro". Neste manual estão ilustradas, de modo didático e de forma direcionada aos Sargentos da Escola de Armas do Exército, formas de identificação, prevenção e tratamento do pé de trincheira, envolvendo as atitudes de retirada das botas, higienização e arejamento dos pés.

Atualmente, a recomendação do Centro de Controle de Doenças Norte-Americano é a de identificar e tratar o pé de trincheira o mais rapidamente possível, mantendo o pé aquecido, limpo e seco. Medicamentos para dor neuropática são de grande valia e o paciente deve ser frequentemente avaliado pelo médico emergencista, o cirurgião vascular e a equipe de saúde. ${ }^{25}$

Como teste de um protocolo de higiene para militares, tentou-se o uso da clorexidina tópica uma vez por semana e de medidas de higiene, incluindo o uso de roupa impregnada por este ativo, mas não foram suficientes para mitigar o percentual de infecções bacterianas por MRSA neste grupo. ${ }^{9}$

Já para a prevenção e tratamento das dermatofitoses nos pés de militares, os agentes antifúngicos são distribuídos entre vários exércitos ao redor do mundo. As figuras abaixo ilustram um creme e um talco antifúngico destinado às tropas norte-americanas:

Entretanto, agentes antifúngicos de largo espectro usados contra Tinea pedis, como o clotrimazol, apresentam resistência fúngica com o uso contínuo, o que se potencializa em indivíduos imunodeprimidos, que pode ser a condição de combatentes. ${ }^{11}$

A 8-iso-prostaglandina, um marcador de estresse oxidativo, 

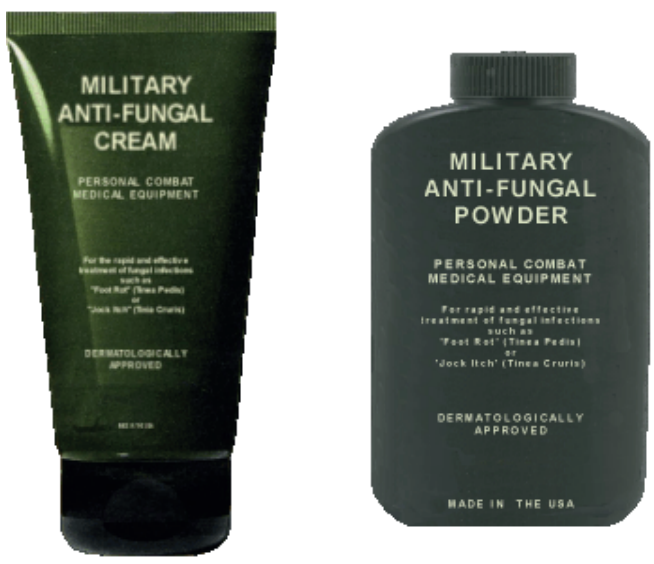

Figura 4. Imagem de produto dermatológico comercial para militares. Fonte: http://www.caplock.com/Anti_Fungal_Treatment.htm. Acessado em 19/4/2021.

está presente em alta concentração nas áreas acometidas por Tinea pedis, sendo que o zinco e o selênio estão depletados nas mesmas regiões. ${ }^{12}$ Sugere-se o uso de antifúngicos conjugados ao zinco e ao selênio para otimizar os resultados dos primeiros em dermatofitoses dos pés.

A segurança e a eficácia da solução de terbinafina a $1 \%$ em aplicação única para o tratamento da Tinea pedis versus placebo na população chinesa. ${ }^{13}$ De acordo com o estudo, uma única aplicação tópica da solução foi eficaz para o tratamento da T. pedis.

Com relação ao antifúngico terbinafina, largamente utilizado para dermatofitoses, verificou-se que a resistência fúngica se estabelece devido às mutações no gene da Esqualeno Epoxidase e que a crescente exposição ao agente antifúngico favorece o aparecimento de cepas resistentes. ${ }^{14}$

Em uma revisão sistemática versando sobre os tipos de tratamento tópico e sistêmico para dermatofitoses, ${ }^{4}$ concluiu-se que o tratamento das dermatofitoses tem se tornado cada vez mais desafiador, com poucos guidelines na terapia tópica e menos ainda nas sistêmicas. A terbinafina parece ser o tratamento de escolha para T. corporis/cruris/pedis para lesões cutâneas limitadas. Para lesões mais extensas, a falta de informações sobre posologia e duração do tratamento é marcante, havendo necessidade de mais pesquisas sobre o tratamento de dermatofitoses.

Testou-se a eficácia do tratamento com água ozonizada e óleo ozonizado versus cetoconazol e naftifine hydrochloride em creme para o tratamento de T. pedis. ${ }^{17}$ Os autores concluíram que a água ozonizada/óleo ozonizado foi tão eficaz quanto o cetoconazol e naftifine, sem os efeitos colaterais adversos destes, especialmente em tratamentos mais longos.

$\mathrm{O}$ óleo ozonizado é tratamento seguro e efetivo para a T. pedis, já que não determina resistência fúngica e não apresenta efeitos colaterais, igualando-se em eficácia ao cetoconazol. ${ }^{18}$

O efeito do gás ozônio foi estudado em 50 cepas de Candida albicans. O gás ozônio foi altamente eficiente na destruição de leveduras de Candida e no impedimento de formação do tubo germinativo. ${ }^{19} \mathrm{~A}$ água ozonizada foi efetiva na destruição de E. coli, S. aureus e de esporos de B. atrophaeus. ${ }^{20}$

O gás ozônio foi eficaz na eliminação de T. rubrum e T mentagrophytes, duas espécies fúngicas comumente encontradas em T. pedis e onicomicoses, eliminando mais de 99,9\% de microrganismos de todas as amostras testadas. $\mathrm{O}$ uso do ozônio, em suas várias formas de utilização, conjugado aos antifúngicos sistêmicos, poderia elevar as taxas de sucesso do tratamento de dermatofitoses. ${ }^{21}$

A eficácia do gás ozônio na eliminação de patógenos de calçados foi testada por meio de um dispositivo de sanitização com base no gás ozônio (Sani Sport, Canadá). Com uma gaze, foram colhidos esfregaços do interior dos calçados de pacientes portadores de onicomicoses e T. pedis e cultivados em ágar e caldo, por 7 dias a $30^{\circ} \mathrm{C}$, antes e depois da sanitização dos calçados. A partir dos esfregaços obtidos dos calçados sanitizados, praticamente não houve crescimento de colônias fúngicas, ou seja, o gás ozônio foi extremamente eficaz na destruição destes microorganismos. ${ }^{22}$ Este dispositivo patenteado opera em modelo fechado, iniciando com a remoção do ar de dentro da câmara e posterior injeção de ozônio, como na foto abaixo:
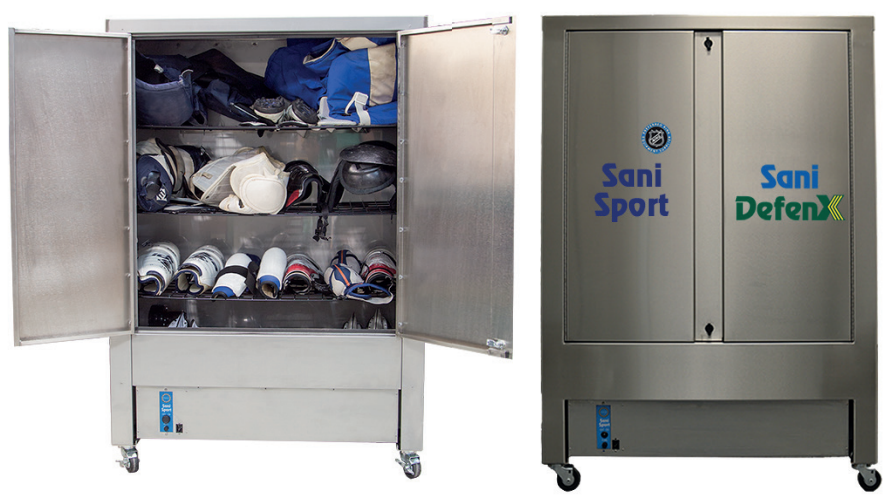

Figura 5. Sanitizador SaniSport. Fonte:https://www.sani-sport.com/sanitizingmachine/supreme.aspx.Acesso em 15 de abril de 2021.

No mercado, encontramos outros modelos de geradores de ozônio que objetivam a desinfecção dos calçados. São de baixo custo, mas de modelo aberto, onde o gás é injetado dentro dos calçados sem anterior remoção do ar. Não foram encontrados apontamentos científicos que garantam a eficácia de tais modelos:

Com o objetivo de prover um modelo in vitro para cultivo 


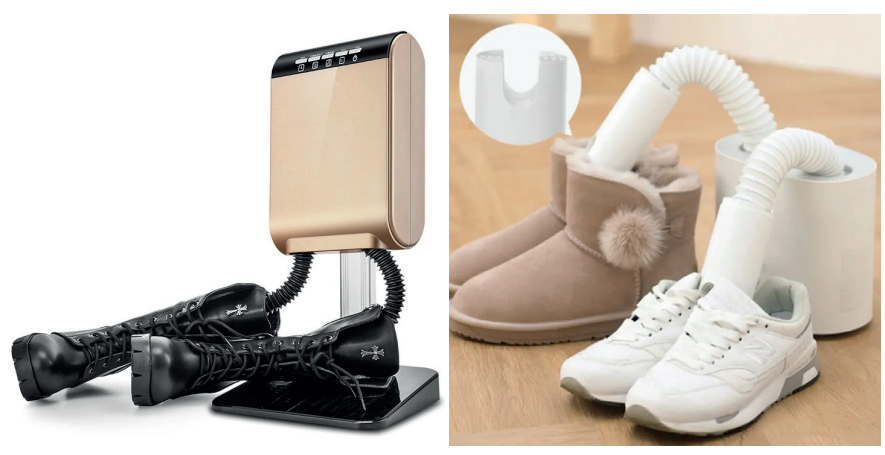

Figura 6. Aparelhos para desinfecção de calçados com gás ozônio. Fonte: https://www.banggood.com. Acessado em 06 de julho de 2021.

de dermatófitos em calçados e testar um dispositivo de desinfecção ultravioleta para calçados, calçados de couro e esportivos foram infectados com $T$. rubrum e T. mentagrophytes, que foram incubados a $35^{\circ} \mathrm{C}$ por 4 a 5 dias. $\mathrm{O}$ interior dos calçados foi raspado com lâminas de bisturi após o tratamento dos sapatos e o conteúdo foi cultivado para testar a eficácia do dispositivo de sanitização. ${ }^{38} \mathrm{O}$ tratamento com ciclos de radiação ultravioleta reduziu a carga fúngica dos calçados.

\section{Discussão}

A revisão da literatura mostrou que as afecções podais entre os militares são bastante frequentes entre os militares, atingindo de 45 a $70 \%$ do efetivo e respondendo por significativas baixas em missões. ${ }^{3,4,5,6,7,8}$ As causas deste fato são o uso contínuo de calçados fechados, como as botas, o que propicia um ambiente com as condições ideais para o desenvolvimento de fungos e outros microrganismos; escasso tempo para remoção dos calçados e arejamento dos pés; higiene deficiente e compartilhamento de ambientes úmidos como vestiários. ${ }^{1,26,27,28,29,30}$

O tipo de afecções podais relatadas em militares também parece ter se alterado ao longo do tempo. ${ }^{10,35}$ Enquanto os relatos de "pé de trincheira" predominaram até pouco depois da II Guerra Mundial, ${ }^{2}$ atualmente as infecções fúngicas e bacterianas ${ }^{32,33,34,35}$ parecem ser as patologias mais frequentes nos Exércitos, segundo o que mostra a literatura. Apesar do "pé de trincheira" ser uma entidade patológica com longo histórico na literatura médica mundial, sua etiologia ainda não é totalmente compreendida, sabendo-se que tanto condições de frio como calor contínuo podem produzir condições para uma neurovasopatia podal, com adicional queratólise e infecção agressiva por microrganismos já presentes nos pés ou nos calçados, culminando com necrose dos tecidos e amputação dos membros inferiores. ${ }^{27,28,29,30}$

A melhoria das condições de saúde dos combatentes atuais, em comparação aos soldados das duas grandes guerras, além da eficácia da prevenção e do tratamento precoce do "pé de trincheira" parecem ter contribuído largamente para o declínio de sua incidência.

No Brasil, em contraste com a literatura internacional, foram encontrados pouquíssimos estudos de medicina militar versando sobre o pé de trincheira, destacando-se um manual de identificação e prevenção desta afecção que foi validado entre militares do Exército Brasileiro ${ }^{10}$. Há vários artigos históricos brasileiros que citam o pé de trincheira em ambiente militar, mas tem como escopo o panorama político-histórico das grandes guerras mundiais e foram excluídos dos artigos selecionados para esta revisão.

Estudos realizados a partir do início do século XXI mostram que as dermatofitoses e infecções bacterianas em pés de militares são as patologias podais que predominam atualmente em militares ao redor do globo, com alta incidência e morbidade, afetando sobremaneira a população militar quando comparada à civil. No Brasil, há apenas dois estudos versando sobre a incidência de dermatofitoses em militares, que apontam taxas de 25 a $83 \%$ nesta população. ${ }^{35,36}$

Enquanto estudos norte-americanos apontam S. aureus, Rhodanobacter terrae

e bactérias atípicas como principais agentes etiológicos de infecções bacterianas em pés de soldados. ${ }^{6}$ Grande parte das dermatofitoses em pés de militares é causada por fungos do gênero Trichophyton, sendo as espécies T. rubrum, $T$. interdigitale e T. mentagrophytes as mais comumente encontradas. ${ }^{35,36}$ Recentes publicações usando biologia molecular puderam identificar várias cepas ou subespécies para T. mentagrophytes e T. rubrum ${ }^{23,24}$ apontando variações genéticas entre elas como responsáveis pela resistência a antifúngicos. Outro estudo usando PCR identificou o T. benhamiae como novo agente etiológico para dermatofitoses podais no Irã. ${ }^{37} \mathrm{O}$ uso desta tecnologia em futuras publicações possibilitará o melhor entendimento etiológico destas afecções e os mecanismos da resistência fúngica aos agentes antimicrobianos.

A prevenção e o tratamento das dermatofitoses e infecções bacterianas podais em militares continuam a ser desafiadores, uma vez que nem sempre medidas de arejamento e higiene dos pés são possíveis de serem realizadas com a devida regularidade em exercícios de campanha e os agentes antimicrobianos, especialmente os antifúngicos, têm sua eficácia comprometida pela resistência fúngica em poucas aplicações, sendo reservados ao tratamento, não à prevenção das afecções. A água ozonizada e o óleo ozonizado mostraram-se tão eficazes no tratamento das dermatofitoses em pés quanto os antifúngicos, tendo o benefício de não induzir resistência fúngica. $17,18,19,20,21$

A descoberta, em 2014, de que o calçado é a principal fonte 
de contaminação microbiana dos pés pôs em xeque as estratégias preventivas centradas somente na higiene podal dos militares e incentivou pesquisas focadas na desinfecção dos sapatos. ${ }^{15,16}$ Mais recentemente, pesquisadores canadenses desenvolveram um aparelho sanitizador de calçados e botas militares por meio do gás ozônio, conseguindo $99,9 \%$ de eficácia na eliminação de T. rubrum e T mentagrophytes. ${ }^{22} \mathrm{O}$ gás ozônio é consagrado mundialmente na desinfecção de água, frutas, verduras, animais, objetos, uma vez que possui propriedades antifúngicas, antivirais, antibacterianas e de degradação de matéria orgânica, não havendo relatos de resistência microbiana a ele ${ }^{19}$ (Zargaran e colaboradores.,2017; Jianyun e colaboradores, 2018). São encontrados comercialmente alguns outros dispositivos que anunciam a desinfecção de calçados por ozônio, por vezes em conjunto com a luz ultravioleta, mas não foi encontrado suporte científico que garanta a eficácia de tais dispositivos em sistema aberto, ao contrário do equipamento de sistema fechado canadense.

\section{Conclusão}

As dermatofitoses e as infecções bacterianas dos pés de militares são na atualidade as afecções podais mais prevalentes neste grupo social, com incidência significativamente maior neste grupo em relação a civis. Já há relatos de avanços significativos na literatura internacional no entendimento da etiologia, prevenção e tratamento do pé de trincheira, bem como a biologia molecular tem contribuído para elucidar o diagnóstico das afecções dermatológicas nos pés. São necessários mais estudos para se entender a epidemiologia destas afecções em militares brasileiros.

Para a prevenção das afecções podais em militares, as estratégias preventivas baseadas na higiene e arejamento dos pés parecem ter melhores resultados quando complementadas pela desinfecção das botas, uma vez que estas são depósitos de microrganismos causadores destas infecções. O gás ozônio parece ser uma ferramenta eficaz na sanitização dos calçados militares e no tratamento das dermatofitoses de pés, mostrando-se tão eficaz quanto os antifúngicos convencionais, sem, contudo, contribuir para a resistência fúngica aos antimicrobianos.

\section{Referências}

1. Kintsurashvili N, Galdava G. Epidemiological characteristics of tinea pedis in the military. TCM\& GMJ. 2018 October; 3(2):8-11.

2. Gajić V. Forgotten great men of medicine--Baron Dominique Jean Larrey (1766-1842). Med Pregl. Jan-Feb 2011;64(1-2):97-100.
3. Hospenthal DR, Crouch HK, English JF. Multidrug-resistant bacterial colonization of combat-injured personnel at admission to medical centers after evacuation from Afghanistan and Iraq. J Trauma Acute Care Surg. 2011; 71(1 Suppl): 52-7.

4. Sahoo AK, Mahajan R. Management of tinea corporis, tinea cruris, and tinea pedis: A comprehensive review. Indian Dermatol Online J. 2016 Mar-Apr; 7(2): 77-86.

5. Chong WS. Dermatology in the military field: What physicians should know? World J Clin Cases. 2013 October 16; 1(7): 208-211.

6. Johnson, RC, Michael W. Ellis MW, Schlett CD et al. Bacterial etiology and risk factors associated with cellulitis and skin abscesses in military trainees. PLoS One. 2016 Oct; 25(11):10.

7. Cohen AD, Wolak A, Alkan M, Shalev R, Vardy DA. Prevalence and risk factors for Tinea pedis in Israeli soldiers. International Journal of Dermatology. 2005; 44(12): 1002-5.

8. Bae JM, Ha B, Lee H, Park CK, Kim HJ, Park YM. Prevalence of common skin diseases and their associated factors among military personnel in Korea: a cross-sectional study. Korean Med Sci. 2012 Oct;27(10):1248-54.

9. Ellis MW, Schlett CD, Millar EV, et al. Hygiene Strategies to Prevent Methicillin- Resistant Staphylococcus aureus Skin and Soft Tissue Infections: A Cluster-Randomized Controlled Trial Among High-Risk Military Trainees. Clin Infect Dis. 2014 Jun;58(11):1540-8.

10. Mendes B. Manual educativo para militares: prevenindo e tratando o Pé de Trincheira. Pouso Alegre. [Dissertação Mestrado Profissional em Ciências Aplicadas à Saúde]. Universidade do Vale do Sapucaí; 2016.

11. Crowley PD, Gallagher HC. Clotrimazole as a pharmaceutical: past, present and future. Journal of Applied Microbiology. 2014; 117: 611--617.

12. Miraloglu $M$, Kurutas EB, Ozturk $P$, Arican O. Evaluation of local trace element status and 8-Iso-prostaglandin F $2 \alpha$ concentrations in patients with Tinea pedis. Biological Procedures Online. 2016; 18:1.

13. Li RY, Wang AP, Xu JH et al. Efficacy and Safety of $1 \%$ Terbinafine Film-Forming Solution in Chinese Patients with Tinea Pedis: A Randomized, DoubleBlind, Placebo-Controlled, Multicenter, Parallel-Group Study. Clin Drug Investig. 2014; 34:223-230.

14. Yamada T, Maeda M, Alshahni MM et al. Terbinafine Resistance of Trichophyton Clinical Isolates Caused by Specific Point Mutations in the Squalene Epoxidase Gene. Antimicrobial Agents and Chemotherapy. 2017 
July; 61(7):115-117.

15. Sasagawa Y. Internal environment of footwear is a risk factor for tinea pedis. Journal of Dermatology. 2019; 46: 940-946.

16. Ishijima SA, Hiruma M, Sekimizu K, Abe S. Detection of Trichophyton spp. from footwear of patients with tinea pedis. Drug Discov Ther. 2019;13(4):207-211.

17. Lu J, Guo M, Ligui $H$ et al. Efficacy of combination of ozonated water with oil for treatment of tinea pedis. Zhong Nan Da Xue Xue Bao Yi Xue Ban. 2018 Feb;43(2):147-151.

18. Menéndez S, Falcón L, Simón DR, Landa N. Efficacy of ozonized sunflower oil in the treatment of tinea pedis. Mycoses. 2002 Oct;45(8): 329-32.

19. Zargaran M, Fatahinia M, Zarei MA. The efficacy of gaseous ozone against different forms of Candida albicans. Current Medical Mycology. 2017; 3(2): 26-32.

20. César J, Sumita TC, Junqueira JC, Jorge AOC, Rego MA. Antimicrobial effects of ozonated water on the sanitization of dental instruments contaminated with E. coli, S. aureus, C. albicans, or the spores of B. atrophaeus. Journal of Infection and Public Health August 2012; 5(4): 269-274.

21. Gupta AK, Brintnell W. Ozone gas effectively kills laboratory strains of Trichophyton rubrum and Trichophyton mentagrophytes using an in vitro test system. Journal of Dermatological Treatment. 2014; 25: 251-255.

22. Gupta AK, Brintnell W. Sanitization of Contaminated Footwear from Onychomycosis Patients Using Ozone Gas: A Novel Adjunct Therapy for Treating Onychomycosis and Tinea Pedis? Drug Discoveries \& Therapeutics. 2019; 13(4):207-211.Jul-Ago 2013; 17 (4): 243-9.

23. Zheng $\mathrm{H}$, Blechert $\mathrm{O}$, Mei $\mathrm{H}$ et al. Whole-genome resequencing of Trichophyton rubrum provides insights into population differentiation and drug resistance. Mycopathologia. 2020; 185: 103-112.

24. Ramaraj V, Vijayaraman RS, Hemanth V, Rangarajan $S$, Kindo AJ. Molecular strain typing of Trichophyton mentagrophytes (T. mentagrophytes var. interdigitale) using a non-transcribed spacer region as a molecular marker. Indian J Med Res. 2017 Nov; 146(5): 636-641.

25. Bush JS, Lofgran T, Watson S. Trench Foot. [StatPearls Publishing Internet]. 2021 Jan. acesso em 13 de julho de 2021;6. Disponível em https://www.ncbi.nlm.nih. gov/books/NBK482364/.

26. Mistry K, Ondhia C, Levell NJ. A review of trench foot: a disease of the past in the present. Clin Exp Dermatol. Janeiro de 2020; 45 (1): 10-14.
27. Imray CH, Richards P, Greeves J, Castellani JW. Nonfreezing cold-induced injuries. J R Army Med Corps. 2011 Mar;157(1):79-84.

28. Jurkovich, GJ. Environmental Cold-Induced Injury. Surg Clin North Am. 2007 Feb;87(1):247-67, viii.

29. Ingram BJ, Raymond TJ. Recognition and treatment of freezing and nonfreezing cold injuries. Curr Sports Med Rep. 2013 Mar-Apr;12(2):125-30.

30. Anand P, Privitera R, Yiangou Y, Donatien P, Birch R, Misra P. Trench Foot or Non-Freezing Cold Injury As a Painful Vaso-Neuropathy: Clinical and Skin Biopsy Assessments. Front Neurol. 2017; 8: 514.

31. Myers TM, Bigler CJ, Maurer MB, Gaither ME, Taylor WM.Tolio: Foot Rot in Grand Canyon River Runners. Wilderness \& Environmental Medicine. 2020; 31(1): 82.

32. Campbell KM, Vaughn AF, Russell KL et al. Risk factors for community- associated methicillin-resistant Staphylococcus aureus infections in an outbreak of disease among military trainees in San Diego, California, in 2002. J Clin Microbiol. 2004; 42:4050-3.

33. Landrum ML, Neumann C, Cook C et al. Epidemiology of Staphylococcus aureus blood and skin and soft tissue infections in the US military health system, 2005-2010. JAMA. 2012; 308:50-9.

34. Frickmann H. Impact of MRSA on the Military Medical Service and Diagnostic Point-of-Care Options for Field Setting. Eur J Microbiol Immunol. 2018 Jun 20;8(2):31-33

35. Leite Jr. DP, Amadio JVRS, Simões SAA et al. Dermatophytosis in Military in the Central-West Region of Brazil: Literature Review. Mycopathologia. 2014 Feb; 177(1-2):65-74.

36. Pereira FO, Gomes SM, Silva SL, Teixeira APC, Lima IO. The prevalence of dermatophytoses in Brazil: a systematic review. J Med Microbiol. 2021 Mar;70(3).

37. Ebrahimi M, Zarrinfar $H$, Naseri A et al. Epidemiology of dermatophytosis in northeastern Iran; A subtropical region. Current Medical Mycology. 2019; 5(2): 16-21.

38. Ghannoum MA, Isham NM. Otimização de um modelo de calçado infectado para a avaliação de um dispositivo ultravioleta desinfetante de calçados. J Am Podiatr Med Assoc. 2012; 102 (4): 309-313. 